\title{
Instrument to assess research projects that apply for a fellowship by the Sociedad Argentina de Pediatria: Validation using the Delphi method
}

\author{
Silvia Caino, M.D. ${ }^{a}$, Paula Dominguez, M.D. ${ }^{b}$, Verónica Aguerre, M.D. ${ }^{c}$ and \\ Vanesa Castellano, M.D. ${ }^{d}$
}

\begin{abstract}
The objective of this study was to validate the format and contents of an instrument to assess research projects that apply for a fellowship by the Sociedad Argentina de Pediatría using an expert consultation technique, such as the Delphi method.

Material and methods. A coordinating group selected a panel of research experts who were members of the Sociedad Argentina de Pediatría, designed, and analyzed each of the rounds of consultations. Semistructured questionnaires were sent by personalized e-mail. Agreement among experts $\geq 80 \%$ was established as the criterion for consensus. At each round of consultation, non-consensual aspects were reformulated and new aspects suggested by experts were included. A measure of stability to conclude the consultation was determined when more than $70 \%$ of experts sustained their opinion in successive rounds.

Results. Thirteen research experts participated in the process. After 3 rounds, the consultation process was concluded. The consensual instrument contains 47 items. In relation to the total score, $10 \%$ corresponds to the general presentation; $40 \%$, to methodological quality; $20 \%$, to relevance and applicability; $20 \%$, to feasibility; and $10 \%$, to the fellow's and director's background.

Conclusions. The format and contents of the instrument to assess research projects that apply for a fellowship by the Sociedad Argentina de Pediatría were validated based on expert consensus and objective assessment criteria were established.

Keywords: Delphimethod, clinical research protocol, educational assessment.
\end{abstract}

http:/ / dx.doi.org/10.5546/ aap.2019.eng.e333

To cite: Caino S, Domínguez P, Aguerre V, Castellano $V$. Instrument to assess research projects that apply for a fellowship by the Sociedad Argentina de Pediatría: Validation using the Delphi method. Arch Argent Pediatr 2019;117(4):e333-e339.

E-mail address:

scaino@garrahan.gov.ar

Funding:

None.

Conflict of interest:

None.

Received: 10-23-2018

Accepted: 1-2-2019

\section{INTRODUCTION}

The Sociedad Argentina de Pediatría is an organization devoted to infant and child health that provides support for research training to young physicians from Argentina through 7 or 8 research fellowships granted each year. The purpose is to improve population health and develop regional capacity to refine research quality.

Approximately $15-20$ projects are submitted each year. As established in the fellowship rules, the jury is made up of assessors from different areas of the Sociedad Argentina de Pediatría who are coordinated by the Subcommittee for Scholarships and Awards. ${ }^{1}$

In recent years, the Subcommittee has worked on adapting the assessment instrument to establish objective selection criteria. In this regard, Albornoz et al., ${ }^{2}$ have pointed out that, sometimes, the lack of objective criteria to assess projects results in assessment inconsistency.

Other authors have observed that, from a measurement perspective, assessment instruments must be objective, clear, understandable for the parties, preferably quantitative, reliable, and valid. ${ }^{3,4}$

In this regard, several guidelines for the critical assessment of original biomedical articles have been described, with variations in the range of items included (20 to 169). ${ }^{5,6}$ However, this is not the case of project assessment for which criteria are not clearly defined. Although most authors have proposed

Collaborators: Enrique Abeyá Gilardon, M.D., José Ceriani Cernadas, M.D., Graciela Demirdjian, M.D., Pablo Durán, M.D., Ramón Exeni, M.D., Fernando Ferrero, M.D., Carlos Figueroa Turienzo, M.D., Facundo García Bournissen, M.D., Ángela Gentile, M.D., Norberto Giglio, M.D., Carlos Grandi, M.D., Horacio Lejarraga, M.D. and Laura Moreno, M.D. 
to assess four protocol aspects (topic relevance, applicability, feasibility, and methodological quality), until now there is no instrument available that has been validated in our setting. ${ }^{7-9}$

The objective of this study was to validate the format and contents of an instrument to assess research projects that apply for a fellowship by the Sociedad Argentina de Pediatría using an expert consultation technique, such as the Delphi method.

\section{MATERIAL AND METHODS Preliminary phase}

First of all, in accordance with the Delphi method, 2 groups were established: coordinating group and expert group.

The coordinating group (SC, PD, VA, VC) was in charge of selecting and inviting experts, adapting the pre-existent assessment instrument, analyzing each round, and supervising the consultation process.

Seventeen experts were invited to participate in the study. An expert was defined as the person in charge of conducting a research, an investigator or a research participant for a renowned national institution, an indexed journal reviewer, and/or a person who had published at least 10 articles in his/her field of work, who was a member of the Sociedad Argentina de Pediatría, and who agreed to participate in the process.

The coordinating group adapted the project assessment instrument, which had been used previously, in accordance with the recommendations by J. Muñiz and E. Fonseca Pedrero (2008). ${ }^{10}$ To define the construct or aspect to be measured, the current rules of the Sociedad Argentina de Pediatría were reviewed and a bibliographic search in Pubmed and Lilacs was done using the following key words: research protocol, research project, expert assessment, peer review. ${ }^{11}$ Fifty items distributed in the following domains were included: relevance/ interest, applicability, feasibility, methodological quality, and overall project presentation. ${ }^{8,12} \mathrm{~A}$ numeric rating scale was proposed arbitrarily. It corresponded to a 5-point Likert scale, where 1 meant non-compliance and 5, full compliance with the item.

Lastly, the first version of the questionnaire was developed (project assessment grid or instrument) and the consultation process was carried out.

\section{Consultation phase}

The instrument's format and contents were validated using the Delphi method, which was the objective of this study. The Delphi method is defined as a method for structuring a group communication process in allowing a group of individuals to deal with a complex problem. The purpose of this technique is to gain consensus or agreement among specialists about the problem proposed instead of letting a single professional make the decision. ${ }^{13}$

The following aspects were subjected to consensus: a) instrument domains and items, b) rating criteria, and c) grid complements.

The consultation process consisted in a series of questionnaire rounds sent by personalized e-mail to each expert between March and September 2017. The initial round consisted in a series of 55 questions with a 5-point Likert scale (from "strongly disagree" to "strongly agree"), and 3 open-ended questions.

The subsequent rounds consisted in reformulating aspects for which no consensus had been reached based on the experts' claims, introducing new aspects for consensus suggested in the previous round, and asking again experts who had not agreed, together with their claims.

Agreement among experts $\geq 80 \%$ was established as the criterion for consensus. To conclude the consultation process, when $>70 \%$ of experts did not change their answers from the previous round, it was considered a measure of stability.

Finally, the list of consensual aspects was reviewed by each expert. Following this process, the final instrument was developed.

The project was approved by the Steering Committee of the Sociedad Argentina de Pediatría.

\section{RESULTS}

A total of 14 out of 17 experts agreed to participate; 13 were from the Metropolitan Area and 1, from Córdoba. One of them was left out because he only answered the questionnaire from the first round. The median length of research experience was 30 years (r: 19-39). After 3 rounds, the consultation process shown in Figure 1 was ended.

\section{a. Instrument domains and items}

Forty-seven items were agreed for inclusion in the assessment instrument; of these, 8 corresponded to the manuscript presentation; 32 , to the methodological quality; 4 , to scientific relevance and applicability; and 3, to feasibility. 
Table 1 describes each item and the level of consensus. During the first round, $87 \%$ of proposed items reached consensus. The most controversial domains were those relative to relevance and applicability.

\section{b. Rating criteria}

The relative importance of the four domains was quantified, as described in Table 2, so that the final assessment of a research project would be the result of adding each of its parts. A total of $91.5 \%$ of experts agreed that the project would be rejected if it did not meet $60 \%$ (r: 40-90) of the methodological quality domain and if it did not comply with all ethical aspects under assessment (100\% of agreement), regardless of the overall score.

Also, it was agreed to include the assessment of the applicant's and the fellowship director's background (92\% and $85 \%$ of agreement, respectively). The median score assigned to the applicant's background was $5 \%$, and to the fellowship director's background, $7.5 \%$ of the total score.

FIGURE 1. Summary, process, consultation

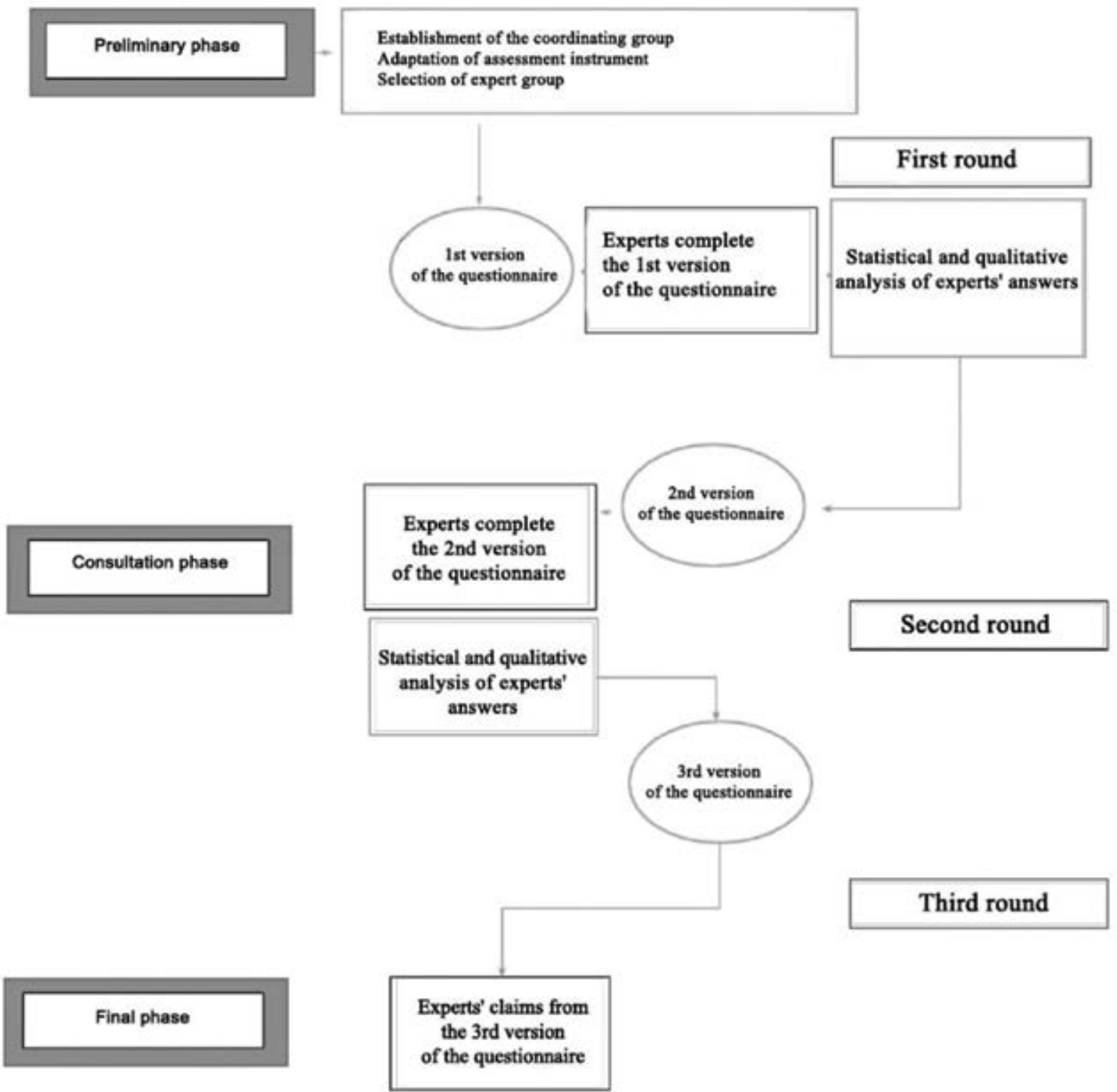

Final version 
TABLE 1. Instrument to assess research projects. Items and domains agreed among experts

\section{Overall presentation}

The pre-established format is observed: A4 paper size, Arial 10 font, maximum of 10 pages (excluding annexes, tables, figures, and bibliography).

Language is adequate and writing is clear and accurate.

Title

Study contents are clearly indicated (research problem and main outcome measures).

Abstract

It allows to identify the study's basic contents.

It is clear and easily understood.

Objectives and hypotheses are included.

The methodological design is clearly described.

It is brief (maximum of 250 words).

\section{Methodological quality}

\section{Introduction}

The research problem is clearly identified and defined.

The reason for selecting the research problem is explicitly stated (no previous studies in our setting, new information will be obtained, other outcome measures will be analyzed, etc.).

The project includes an already existing theoretical framework and/or proposes its own theoretical framework according to the research problem.

The hypotheses describe, in a clear, accurate and brief manner, a relation (or difference) between two or more study outcome measures.

\section{Objectives}

The objectives are adequate to the research question.

The objectives are observable, specific, measurable, and feasible.

\section{Study design}

The design is in accordance with the study objectives.

The design is adequately described.

\section{Population}

The study target and accessible populations are identified and described in detail (inclusion, exclusion, and elimination criteria).

Sampling is explained (random probability, non-probability, non-random, etc.).

The sample size calculation is reported. If not possible, the number of cases estimated for inclusion in the fellowship period is described.

Outcome measures

The project outcome measures are selected according to the proposed study objectives and design.

The study outcome measures are defined operationally.

The methods to analyze outcome measures are detailed.

Dependent and independent outcome measures are defined.

Confounding outcome measures are acknowledged, and their control is indicated.

\section{Data collection}

Data collection instruments are adequate to the study design.

The instrument's validity and / or reliability are described.

Data collection steps (who, where, when, as well as registration forms) are clearly described.

The data collection procedure is adequate.

\section{Data analysis}

The data analysis plan is described and explained.

The selection of statistical analysis procedures is valid to answer the research question.

Potential biases that may limit the validity of results are taken into account. 


\section{Ethical aspects}

The project follows the ethical guidelines for research in children (and for the assessment of the risk/ benefit ratio).100

The process to protect anonymity and data confidentiality is explicitly stated. 100

$\begin{array}{lr}\text { The informed consent (and assent, if applicable) is attached. } & 100\end{array}$

The informed consent procedure is described.

3. Scientific relevance and applicability

The study results will provide new points of view regarding the research problem.

The research is justified to fulfill an information gap.

The problem is important, current, focused on relevant pathologies (due to their frequency, the burden caused on the affected population or their social and health impact).

The topic corresponds to one suggested by the Sociedad Argentina de Pediatría in relation to the fellowship announcement.

The study results may be applied in the public health setting or in clinical practice in terms of prevention,

diagnosis, treatment or prognosis of the topic of interest.

4. Feasibility

The study conduct plan (task distribution, time for the project) is feasible during the year of the fellowship. 100

The estimated number of research subjects can be enrolled during the fellowship period. 100

The work setting (laboratory, equipment, etc.) is adequate to conduct the project.

TABLE 2. Rating criteria

\begin{tabular}{lcccccc}
\hline & $\begin{array}{c}\text { Overall } \\
\text { presentation }(\%)\end{array}$ & $\begin{array}{c}\text { Methodology } \\
(\%)\end{array}$ & $\begin{array}{c}\text { Relevance/ } \\
\text { applicability }(\%)\end{array}$ & $\begin{array}{c}\text { Feasibility } \\
(\%)\end{array}$ & $\begin{array}{c}\text { Fellow's résumé } \\
(\%)\end{array}$ & $\begin{array}{c}\text { Fellowship } \\
\text { director's } \\
\text { résumé }(\%)\end{array}$ \\
\hline Mean & 10.4 & 37.1 & 18.8 & 18.3 & 7.3 & 8.1 \\
Median & 10 & 37.5 & 17.5 & 20 & 5 & 7.5 \\
1st quartile & 8.8 & 27.5 & 10 & 18.8 & 5 & 4.3 \\
3rd quartile & 10 & 42.5 & 21.3 & 20 & 10 & 11.3 \\
\hline
\end{tabular}

$\%$ of final score.

\section{c. Grid complements:}

All experts agreed that the instrument should include a field for the assessor to make comments deemed relevant about the items with an unfavorable score; $92.8 \%$ agreed that comments should be subsequently submitted to the applicants for project improvement. Also, $84.6 \%$ of experts agreed that the instrument should include supplementary instructions (glossary) with methodology-related terms to facilitate the assessor's task.

The following aspects did not reach consensus after consultation rounds: 1) Rating scale for each item: $66.6 \%$ of experts agreed on the 5-point Likert scale, whereas others preferred a 3- and 4-point Likert scale. 2) Total score: $55.4 \%$ of experts preferred to sum each item; others, to obtain an average of each domain and then sum such averages; while some experts suggested assessing methodological quality on the one side and relevance on the other, and then making an overall decision. 3) Item general opinion of the assessor (the project is a candidate or not for a fellowship): only $76.9 \%$ of experts agreed to include this item; those who disagreed stated that their decision was based on item subjectivity. 4) Processing of the not applicable item: $63.6 \%$ of experts preferred to recalculate the total domain score leaving out this item, whereas others preferred to assign the highest or lowest score to this item.

All experts agreed that the consensual instrument could be easily completed, was written in a clear and relevant language, and that a description of each item would facilitate the assessor's task.

\section{DISCUSSION}

After 3 rounds of consultations, the expert group considered that the instrument's contents were valid to assess research projects that applied for a fellowship by the Sociedad Argentina de Pediatría. The instrument's final version included 47 items conveniently analyzed and distributed into 4 domains.

The main differences between the recently agreed instrument, accepted by experts, and the previous one were, on the one side, the inclusion 
of a series of items to be assessed within each domain, which allows assessors to use the same quality criteria. On the other side, the overall presentation domain was included.

Although it does not seem reasonable to reject a good project based on format inadequacy, there appears to be a certain reverse relation between a deficient presentation and scientific quality, probably because the main limitation in a project preparation is related to the efforts made by investigators. ${ }^{6}$

As proposed by other assessment agencies, $100 \%$ of experts agreed to include qualitative comments in the final report regarding items with a low score, which would serve as the basis to justify the rating given to the project. ${ }^{14}$ In addition, it was agreed that such comments would be subsequently submitted to researchers to inform them of the assessment results in order to improve the project.

The feasibility assessment of a project requires evaluating the research team capabilities and the possibility of conducting the protocol. Guallar et al., state that the best way to guarantee that a project will be adequately completed is researchers' demonstration that they have completed similar projects before. ${ }^{6}$ In this regard, experts agreed to include the assessment of the applicant's and the fellowship director's background. However, since these fellows are aimed at pediatric medical residents, it was agreed that the score corresponding to the fellow's background would account for $5 \%$ of the total score.

This study proposes an instrument to facilitate assessors' task by making assessment criteria homogeneous. It does not pretend to be a rigid analysis element but to facilitate the work of assessors, respecting, at all times, the experts' individual opinions in a specific area of knowledge. Likewise, it aims at having researchers know the criteria used to assess their projects, which will help to encourage an improvement in quality.

One of the weaknesses of this study is that the selected experts are all members of the same scientific society and, therefore, this instrument should be validated for its use in other institutions. However, its strength lies in the fact that it was developed for its use within the Sociedad Argentina de Pediatría based on the characteristics typical of the projects submitted for each fellowship announcement.

Lastly, it is worth noting that this is a dynamic instrument, and its contents should be revised whenever it is considered timely in accordance with the advances in scientific research, publication, and dissemination practices. The instrument's reliability, usefulness, and level of acceptance will be analyzed in a second phase.

\section{CONCLUSIONS}

The format and contents of the instrument to assess research projects that apply for a fellowship by the Sociedad Argentina de Pediatría were validated based on expert consensus and objective assessment criteria were established.

\section{REFERENCES}

1. Sociedad Argentina de Pediatría. Reglamento de Becas. [Accessed on: January $\left.4^{\text {th }}, 2019\right]$. Available at: www.sap.org. ar/docs/ profesionales / becaspremios / REGLAMENTO_ BECAS_2015.pdf.

2. Albornoz M. Evaluación en ciencia y tecnología. Revista Perspectivas Metodológicas. 2003; 3(3):585.

3. Alvez de Lima A, Barredo C, Baratta S, Castillo Costa $\mathrm{Y}$, et al. Validity, reliability, feasibility and satisfaction of the Mini-Clinical Evaluation Exercise (Mini-CEX) for cardiology residency training. Medi Teach. 2007; 29(8):78590.

4. Bordage G, Brailovsky C, Carretier H, Page G. Content validation of key features on a national examination of clinical decision-making skills. Acad Med. 1995; 70(4):27681.

5. Chan AW, Tetzlaff JM, Altman G, Laupacis A, et al. Declaración SPIRIT 2013: definición de los elementos estándares del protocolo de un ensayo clínico. RevPanam Salud Pública. 2015; 38(6):506-14.

6. Guallar E, Conde J, De la Cal MA, Martín-Moreno JM. Guía para la evaluación de proyectos de investigación en ciencia de la salud. Med Clin (Barc). 1997; 108:460-71.

7. Rodríguez PuyolD, Arribas Gómez I, CorbíLópez A, Lamas $S$, etal. Evaluación de proyectos deinvestigación en ciencias de la salud. El punto de vista de la Agencia Nacional de Evaluación y Prospectiva. Madrid: Ministerio de Ciencia, Innovación y Universidades; 2010. [Accessedon: January $\left.4^{\text {th }}, 2019\right]$. Available at: http://www.idi.mineco.gob.es/ stfls / MICINN/Investigacion/FICHEROS / Cvn_Anep/ criterios_de_evaluacion_en_cc_de_la_salud.pdf.

8. Rodríguez del Águila M, Pérez VicenteS, Sordo delCastillo L, Fernández Sierra M. Cómo elaborar un protocolo de investigación en salud. Med Clin (Barc). 2007; 129(8):299302.

9. Bobenrieth-Astete MA. Lectura crítica de artículos originales en salud. Med Fam Andal. 2001; 2:81-90.

10. Muñiz J, Fonseca-Pedrero E. Construcción de instrumentos de medida para la evaluación universitaria. Revista de Investigación en Educación. 2008; 5:13-25.

11. Crozier F, Teixeira P, Van de Velde P, Zarina I. Evaluación por parte de la agencia ENQA: Agencia de calidad y prospectiva universitaria de Aragón (ACPUA). Aragón: ENQA; 2016. [Accessedon: January 4 ${ }^{\text {th }}, 2019$ ]. Available at: http: / / www.aragon.es/estaticos / GobiernoAragon/ A CPU A / Documentos / A reas_Intern/E v_E NQA _ ACPUA.pdf.

12. Subcomisión de Investigación. Guía para elaborar un 
proyecto de investigación. Arch Argent Pediatr. 2011; 109(4):371-6.

13. Linstone HA, Turoff M (eds.). The Delphi Method, Techniques and Applications. Boston: Addison-Wesley Educational Publishers Inc; 1975.
14. Fund For Scientific Research. Evaluation Guide Rules of procedures for ex-ante evaluation, selection and granting. 2017. [Accessed on: January $\left.25^{\text {th }}, 2019\right]$. Available at: http:/ / www.fnrs.be/docs/Reglement-et-documents/FRS-FNRS_ Guide_Evaluation_EN.pdf. 